\title{
Sign Language in South Africa: Some research and clinical issues
}

\author{
Claire Penn PhD (Witwatersrand) \\ Robyn Lewis BA (Log) (Rand), BA (Soc. Science) UNISA, LTCL \\ Andrea Greenstein BA (Sp \& H Th) (Witwatersrand) \\ Department of Speech Pathology and Audiology, \\ University of the Witwatersrand
}

\begin{abstract}
This article describes the variations of aspects of visual language of the deaf which have been well researched in other countries and which are hypothesized to exist in South Africa. The results of a study conducted on the signing of a group of deaf school children in Johannesburg are described. The signs used by these subjects for twelve lexical items differed from the signs said to be representative of the South African deaf community as a whole. Research and clinical implications are presented.
\end{abstract}

\section{OPSOMMING}

Hierdie artikel beskryf die variasie wat bestaan in aspekte van visuele taal van die dowe wat deeglik bestudeer is in ander lande en wat waarskynlik ook in Suid-Afrika bestaan. Die resultate van 'n ondersoek na die gebarestelsel in 'n groep dowe skoolkinders in Johannesburg word beskryf. Die gebare van twaalf leksikale items wat hierdie kinders gebruik verskil van die tekens wat aanvaar word as verteenwoordigend van die Suid-Afrikaanse dowe gemeenskap as geheel. Navorsing en kliniese gevolgtrekkings word aangebied.

For the past two decades, sign language has enjoyed the increasing attention of researchers and clinicians alike. This field of study has been particularly active in America where, since Stokoe's extensive research $(1976,1978)$ there has been a widespread acceptance of sign language as the heritage of a distinct social minority - the Deaf* Community, with its own culture and norms. Stemming from an increased consciousness of the rights of minority groups, the view of the deaf individual as 'bilingual' is an increasingly popular one.

With regard to the South African position on sign language, the writers believe that two main issues need resolution. First, there is the need to determine the nature and variety of sign languages used by the South African deaf community and whether this is similar or distinct from more widely researched systems such as American Sign Language (ASL). Second, the implications of this research for deaf educators need to be considered. An attempt will be made to raise some issues relevant to these points. By way of a background to preliminary experimental evidence, some terminological and conceptual issues in sign language will be introduced.

Perhaps the most encompassing model of ASL is the one proposed by Woodward in 1972 who pointed out the notion of a "Sign Language Continuum". This is represented schematically below (see Fig. 1).

The one extreme of the continuum is occupied by ASL which is the visual gestural language used by the deaf in North America. It has a formal structure, it is systematic, rulegoverned and is strongly 'arbitrary' in that there is no resem-

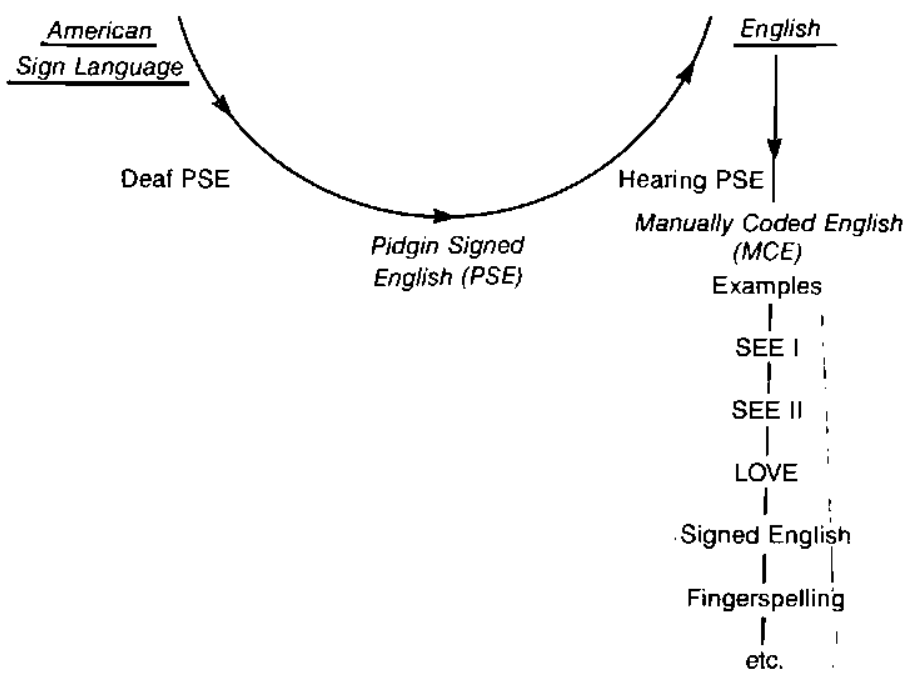

Figure 1 American Sign Language Continuum (after Woodward, 1972).

blance between the form of a symbol and the thing it stands for (Klima and Bellugi, 1979). Derived from this formal language and the necessity for communication between deaf and normal hearing individuals, a Pidgin Sign Language (PSL) has developed naturally, incorporating elements of bóth English and ASL. Like any Pidgin language, the reduction and mixing of two languages (in this case ASL and English) result in new structures. As the continuum approaches Pidgin Signed English (PSE), grammatical features of ASL are replaced by English

* The term "dear" is used throughout this article to denote individuals with a severe or profound hearing loss. 
features such as grammatical markers and word order (Baker and Cokely, 1980).

It is of note that many writers mistakenly confuse PSE with pure sign language. A further point of confusion arises when examining Manually Coded English (MCE), another point on the Sign Language continuum. MCE refers to the development of several codes which attempt to represent manually, spoken English syntax, and are hence distinct from either ASL or PSL. Such systems include Signed English, Linguistics of Visual English (LOVE), Seeing Essential English (SEE) and the Rochester Method (USA) and the Paget Gorman System (U.K. and South Africa). Such manually coded systems had their origin in the increased awareness amongst educators that for the majority of severely and profoundly deafened children, the oral system alone has failed to teach functional English, either written or spoken, and that communication through a visual mode has many advantages (Conrad, 1979). Hence the notion of 'Total Communication' has evolved incorporating manually coded systems as well as lip reading, auditory training, speech teaching, etc.

To summarize, there are discrete differences between ASL, PSL and MCE, all of which need to be taken into account by the researcher and clinician dealing with the deaf. While sign language per se is a pure language found among deaf users, within educational contexts (i.e. where the deaf mingle with hearing individuals) there is a strong likelihood of observing PSL or a manual system which has been formally introduced as an educational option.

In South Africa, there is clearly a wide variety of visual language being used by the deaf. According to Axelrod (1983) the first people to bring a sign system to this country were the Irish Sisters over a century ago, but details regarding the nature of this sign language are unknown. Due to the discrete educational policies at present existing in the country, many separate systems are probably in existence. For Black school children a manuál code based on the Paget Gorman system is used (i.e. all Déaf schools falling under the control of the Department of Education and Training use this code). White deaf children by contrast, have to date not been permitted to use any signing system for formal education. The same situation exists for $\mathrm{Col}-$ oured and Indian communities. The South African National Council for the Deaf, clearly niot unaware of the discrepancies in educational policies and the urgent need for sign language research, has recently established a Communications Committee to investigate the whole issue of sign language in this country. An attempt is being made to establish a "uniform sign language system in South Africa' (Viljoen, 1982). A book, 'Talking to the Deaf' (Nieder-Heitman, 1980) is currently being promoted as representative of signs used by the majority of deaf South Africans. This is indeed a praiseworthy preliminary effort in a field so lacking in documentation but we believe that the stand taken is premature. First, little attempt has been made to describe the syntactic structure of the visual language presented in the text. Second, there is no clear indication as to the research methods employed to establish the stated 'majority' representativeness of the signs. Further, the source of many of the photographs is not local but an overseas one (the Gestuno system). Finally and most important, it would scem highly likely, in view of the preceding discussion that no single South African sign language exists.

No one working within the deaf community of South Africa, not least the deaf individuals themselves, can deny the existence of a seemingly rich spontaneous sign language which is used in at least some conversational contexts. What is at issue however is the potential variability of such visual language amongst different users. Further, sign language as such, is clearly distinct from the manually coded systems used by some groups and undoubtedly shows considerable divergence according to culture, demography and sociological factors. Languages develop, they are determined by history, by culture and by geography, and cannot be artificially constructed. In view of the above, it is, we suggest, essentially impossible and certainly unproductive to hypothesize the existence of a uniform sign language in South Africa. As evidence for the above suggestions, some preliminary field work into the use of deaf sign language in South Africa will now be described.

\section{PRELIMINARY EXPERIMENTAL EVIDENCE}

The aims of this study* were first to describe the signs representing a number of lexical items used by deaf children attending a White residential school for the deaf in Johannesburg in order to determine whether the use of these signs is standard within the school population, and second to determine whether these signs differ from those proposed to be the "Standard" South African signs as described by Nieder-Heitman (1980).

\section{METHOD}

Forty deaf subjects ranging between the ages of 5-19 years were selected. Subjects were congenitally deaf (loss of $80 \mathrm{~dB}$ or more in the speech range) and were all boarders at the deaf school, thus ensuring that subjects interacted within the same educational and social environment.

Twelve lexical items were selected according to the following criteria:-

1) All items were required to appear in Nieder-Heitman's (1980) dictionary "Talking to the Deaf".

2) Lexical items were selected in terms of their frequency, use and relevance within the subjects' environment.

3) Lexical items thought to be represented by highly iconic signs were eliminated in order to avoid the use of natural gestures.

4) Nouns, verbs, adjectives and prepositions were selected. It has been suggested that the verb system of any language forms the core of every utterance (Wilbur 1976, p. 439) and it is the nouns, prepositions and adjectives which expand the verb phrase into a meaningful language unit.

Three words for each part of speech were selected as follows:-

$\begin{array}{ll}\text { Nouns } & : \text { Dog, Mommy, Tree } \\ \text { Verbs } & : \text { Bathing, Jumping, Sitting } \\ \text { Adjectives } & : \text { Yellow, Old, Happy } \\ \text { Prepositions } & : \text { On, in front of, to }\end{array}$

* The results reported here are based on a research project undertaken in the Departinent of Speech Pathology and Audiology, University of the Witwatersrand, by the third author. 
Only single lexical items, out of syntactic context, were investigated. Stokoe (1978) suggests that when encountering a new language one should commence by comparing vocabulary items. Subjects were individually presented with a picture card and corresponding written stimuli representing the respective signs. All signing was video recorded and analysed according to the following variables:-

- Reported Laterality

- Age

- Dominant hand used

- Correspondence to South African Signs (Nieder-Heitman 1980)

Data was analysed according to 3 cheremes (equivalent to the phonemes of spoken language) as described by Stokoe in Wilbur (1976, p. 441):-

$$
\begin{aligned}
& \text { TAB (Tabula) } \quad-\text { location on or near the body } \\
& \text { where the sign is being made } \\
& \text { DEZ (Designator) }- \text { the configuration of the hands } \\
& \text { SIG (Signation) } \quad-\text { the movement aspect of the } \\
& \text { hands. }
\end{aligned}
$$

All data was tallied according to a percentage. The sign for each lexical item was interpreted as occurring in the majority of Ss if it occurred in more than half the group.

\section{RESULTS}

Table I represents the percentage of subjects using a standard sign together with an indication of their correspondence (or otherwise) with the "South African" sign. This table further demonstrates the dimensions along which the signs differ.

Results indicate that for the twelve lexical items an average of $75 \%$ of the Ss are utilizing a standard system of signs which differ from those described by Nieder-Heitman as representing the South African signs. The mean percentage of subjects utilizing the signs concurs with the findings of Marcowicz (1972) who refers to a study by Best (1972) which reported that $78.2 \%$ of deaf children within an oral school used sign language. The results of the present study also support suggestions in the literature that signs are non-uniform throughout the world (Battison et al., 1976). It is of note that the subjects' signs for only two of the lexical items ('old' and 'happy') approximate the socalled hypothesized standard. For the other lexical items, there is a high level of agreement between Ss for all except one item ('in front of') where considerable variation occurred. The fact that marked differences occurred between the standard signs used by the deaf subjects and the South African signs, reinforces the viewpoint that the signs of the subjects are not simply dialectal variations of the basic South African sign but completely different entities. Six of the signs differed by all three cheremes from Nieder-Heitman's (1980) hypothesized standard and the remaining four signs by at least one chermee. Such variation is further illustrated by the examples in Figure 2 .

Since an average of only $6.2 \%$ of the subjects used the signs from the manual, it is impossible to conclude that there is any close resemblance between the cheremic configurations of the deaf subjects' signs and those appearing in the manual, at least for the signs studied. The subjects appear to have their own unique system which is not idiosyncratic to each individual but is representative (to differing extents) of the group studied as a whole. Certain variations did occur among the subjects but these occurred in a small number of subjects only and were close approximations to the more standard signs. The items on which there was somewhat wider variation were 'jumping', 'sitting' and 'in front of. The former two signs ('jumping' and 'sitting') showed variation from gross iconic gesture involving all four limbs to highly arbitrary signs (i.e. signs where there is no resemblance between sign and meaning (Baker and Coke$1 y, 1980)$ ). The variations observed as a function of these dimensions are illustrated below (see Figure 3).

It was possible to see a developmental trend in this data in that younger subjects in the group were more likely to use iconic variations for these two signs. Though this could not be

Table 1 Percentage of subjects using standard signs for the lexical items investigated

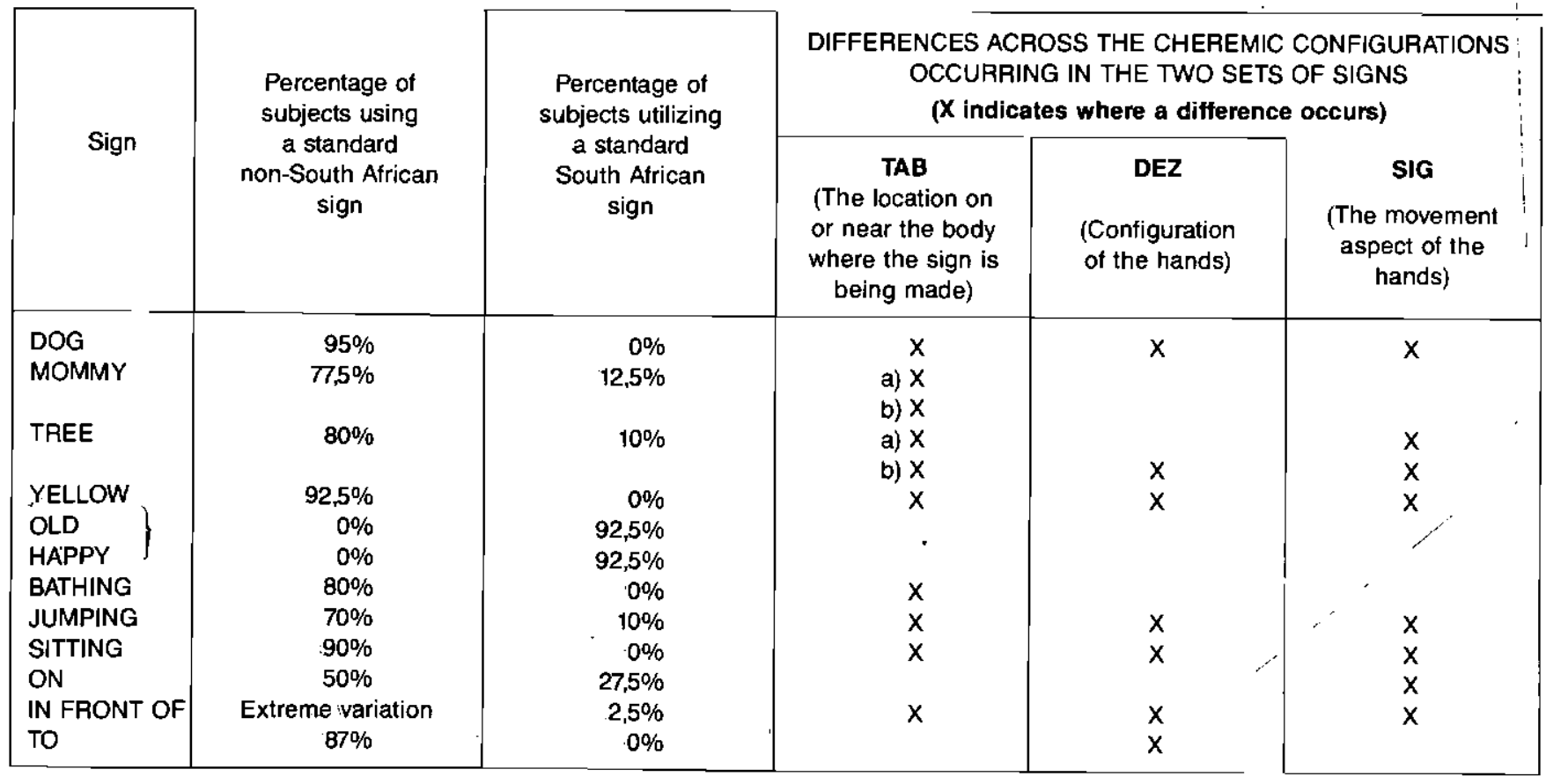


Lexical
Item

Dog

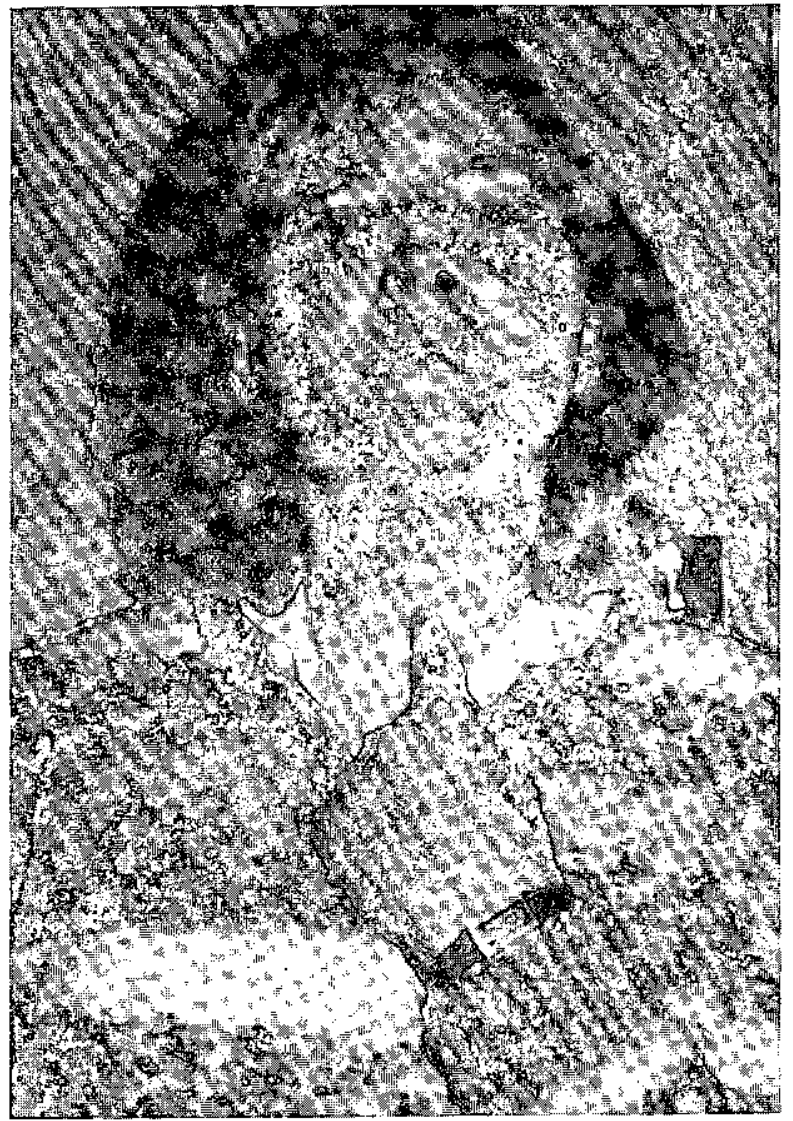

South African "standard"

(after Nieder Heitman, 1980)

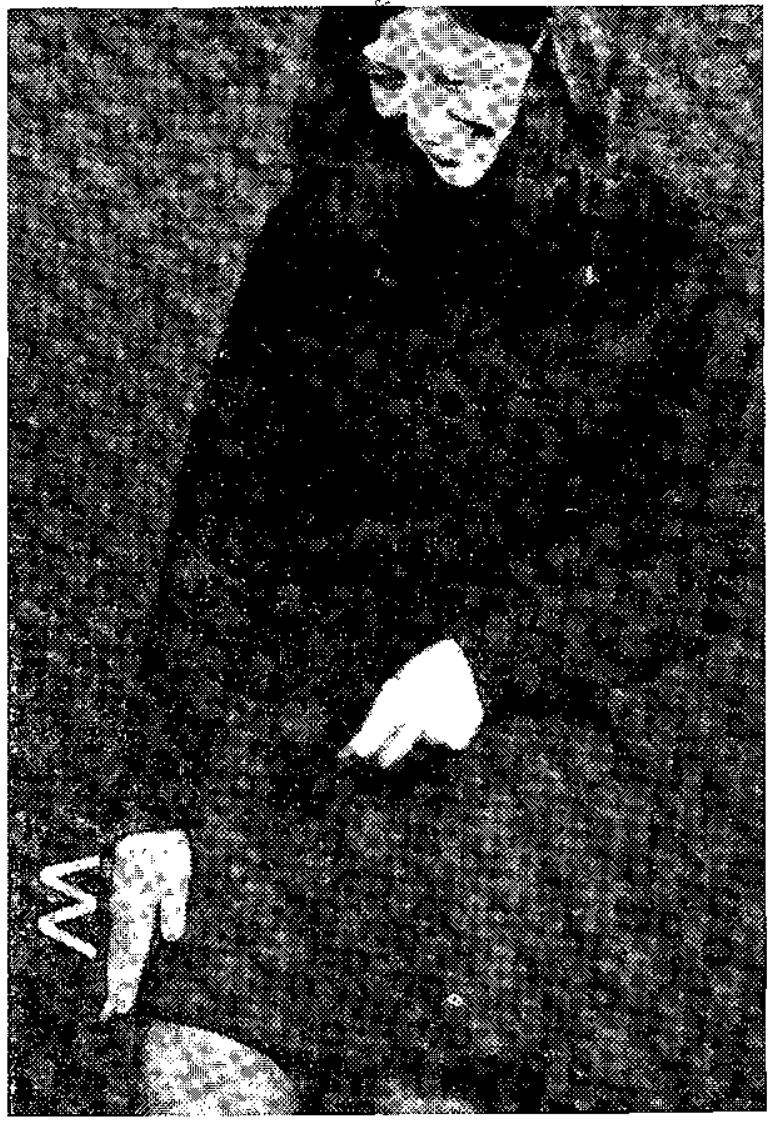

Yellow
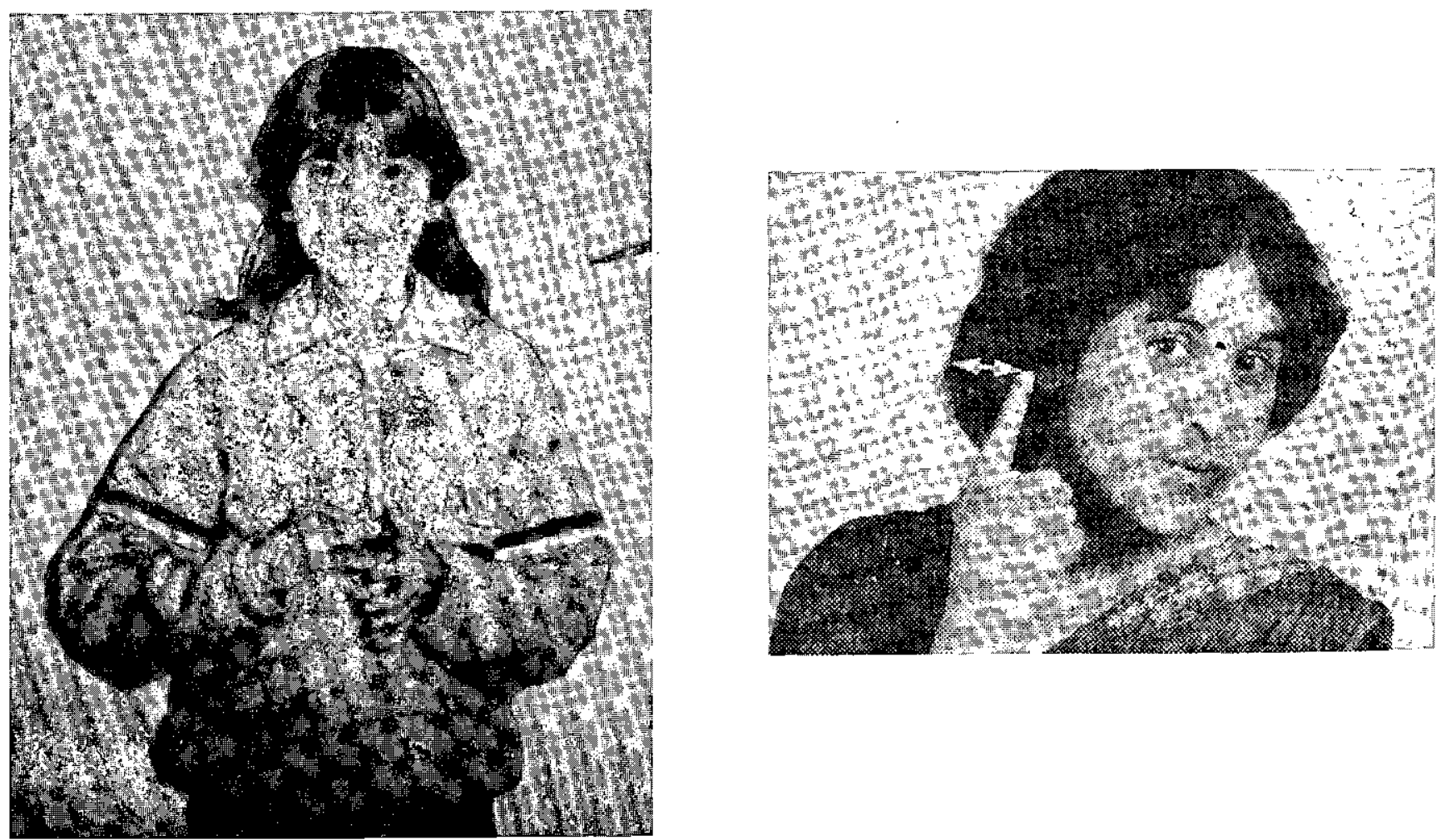

Figure 2 Differences between signs used by subjects and those hypothesised to be the South African standard, for two lexical items.

Die Suid-Afrikaanse Tydskrif vir Kommunikasieafwykings.s, Vol. 3I, 1984 
JUMPING Hands in neutral position; Jumping movement; Legs involved

\section{SITING Sitting movement} by bending knees; hands not involved
Clenched fists

Bent elbows;

Bend elbows back as knees are bent
Hand in ' $V$ ' position

Move hand up and down (as if jumping) on back of opposite hand

Clenched fists; bent elbow

Twist wrist backwards

Figure 3 Variations in signs used for lexical items “Jumping” and "Sitting” as a function of the Iconicity-Arbitrariness Continuum

statistically confirmed in the present study (due to the nature of the group studied) this suggested trend does support the idea that signs, just like spoken languge, develop along a specific route (Wilbur, 1976).

The variability characterizing the sign 'in front of' might be explained in terms of the fact that the form of certain signs is dependent on context (Klima and Bellugi, 1974, p.41). For example according to these authors 'sitting in front of the class' may be signed differently from the boy stood in front of the girl'. Since in the present study, the stimuli were not presented in a linguistic context, the subjects' own interpretations was not accounted for. This possibly accounts for the observed variations evident for this particular sign.

Further explanation for variation in certain signs undoubtedly comes from the observation made previously that when the deaf come into contact with hearing individuals, differing modifications of the sign may take place (i.e. a type of Pidgin signing).

As has been previously mentioned, the fact that the writers investigated only isolated lexical items limited the study in view of the fact that the syntax and rules of these signs could not be studied. However, certain features emerged within the signs used by subjects. These features correspond to those features which serve to make American Sign Language a syntactic linguistically sound language. They are:-

1) Iconicity and Arbitrariness e.g. the signs 'jumping' and 'sitting'.

2) Phonology (Cheremes) e.g. the Tab, Dez and Sig configuration evident in each sign.

3) Symmetry and Dominance.

4) The suggestion of a developmental pattern for certain signs.

The results of this study have thus indicated that there appears to be a difference between selected signs used by the deaf subjects investigated - a sub-group of the South African Deaf population, and those signs proposed by Nieder-Heitman (1980) to be representative of all signs used by various ethnic groups in South Africa.

The variations that exist among these two sets of signs are not merely simple ones, but variations which are standard and arbitrary and which differ markedly from one another.

\section{DISCUSSION}

The above experimental evidence serves to illustrate that, at least for the sample tested, there is a lack of conformity with the signs included in the sign language system proposed to be representative of sign language users in South Africa. It therefore seem logical to conclude that in other deaf popula- tions in this country who stem from discrete language groups and educational backgrounds, a similar divergence from the hypothesized standard might exist. Such a finding naturally awaits experimental confirmation but is certainly not unexpected in terms of the theoretical and research considerations discussed previously. It does, however raise some central and pressing clinical and research implications for the study of sign language and its variants in South Africa.

The current attempt to unify South African sign language systems (at different points on the sign language continuum) seems both scientifically and pragmatically questionable. Rather what seems indicated is a nation-wide investigation of the existing dialectal variations in South Africa and a systematic and academic attempt by linguists, sociologists, anthropologists and members of the deaf community to illustrate that the visual language used by the South African deaf is a unique set of phenomena, as arbitrary as rule-governed, as variable and as rich in cultural and linguistic heritage as any other sign system in the world.

The implications arising out of this clearly have relevance to deaf educational policy in South Africa. Though the writers believe strongly in the benefits of a manual code as a supplement to teaching language to the deaf individual; this manual code will clearly have to depend on the existing lexicon and systems used by each individual deaf group in South Africa. The systems which should be adopted will depend on a number of factors and may in fact be fairly similar, or at the other 'extreme, as diverse as the existing spoken languages in this country. Hopefully it will not be political policies which will determine the eventual adoption of coding systems into educational programmes. Rather, the prime concern should be the criterion of effectiveness to the deaf individual. We have a commitment to serve the community in the best way possible and to this end we hope that considerable efforts will be made in the future to investigate this promising yet essentially unexplored field of research.

\section{REFERENCES}

Axelrod, C. Chaplain to the Deaf, Johannesburg. Personal communication, 1983.

Baker, Charlotte \& Cokely, Dennis. American Sign'Language. T.J. Publishers, 1980.

Battison, R.M. \& Jordan, I. King. "Cross-Cultural Communication with Foreigners" in Sign and Culture. William C. Stokoe (Ed.). Maryland: Linstok Press 1980.

Conrad, R. The Deaf School Child. New York: Harper \& Row, 1979. 
Klima, Edward, \& Bellugi, Ursula. The Signs of the Language. Harvard: Harvard Univ. Press, 1979.

Markowicz, Harry. "Some Sociolinguistic Consideration of A.S.L." in Sing and Culture. William C. Stokoe (Ed.) Maryland: Linstok Press, 1980.

Nieder-Heitman, N. Talking to the Deaf. Pretoria: Government Printers, 1980.

Stokoe, W.C.: "The Study and Use of Sign Language". Sign Language Studies, 1976, 10, 1-36.
Stokoe, W.C. Sign and Culture. Maryland: Linstok Press, 1978. Viljoen, Ds. Editorial in The Silent Messenger. S.A. National Council for the Deaf, Vol. 5(3), 1982.

Wilbur, R.B. "Linguistics of Manual Language and Manual Systems". In Communication Assessment and Intervention Strategies. L.L. Lloyd (Ed.) Baltimore: Univ. Park Press. 1976.

Woodward, J. "Implications for Sociolinguistic research among the Deaf." In Sign Language Studies I, 1972. 1-7. 


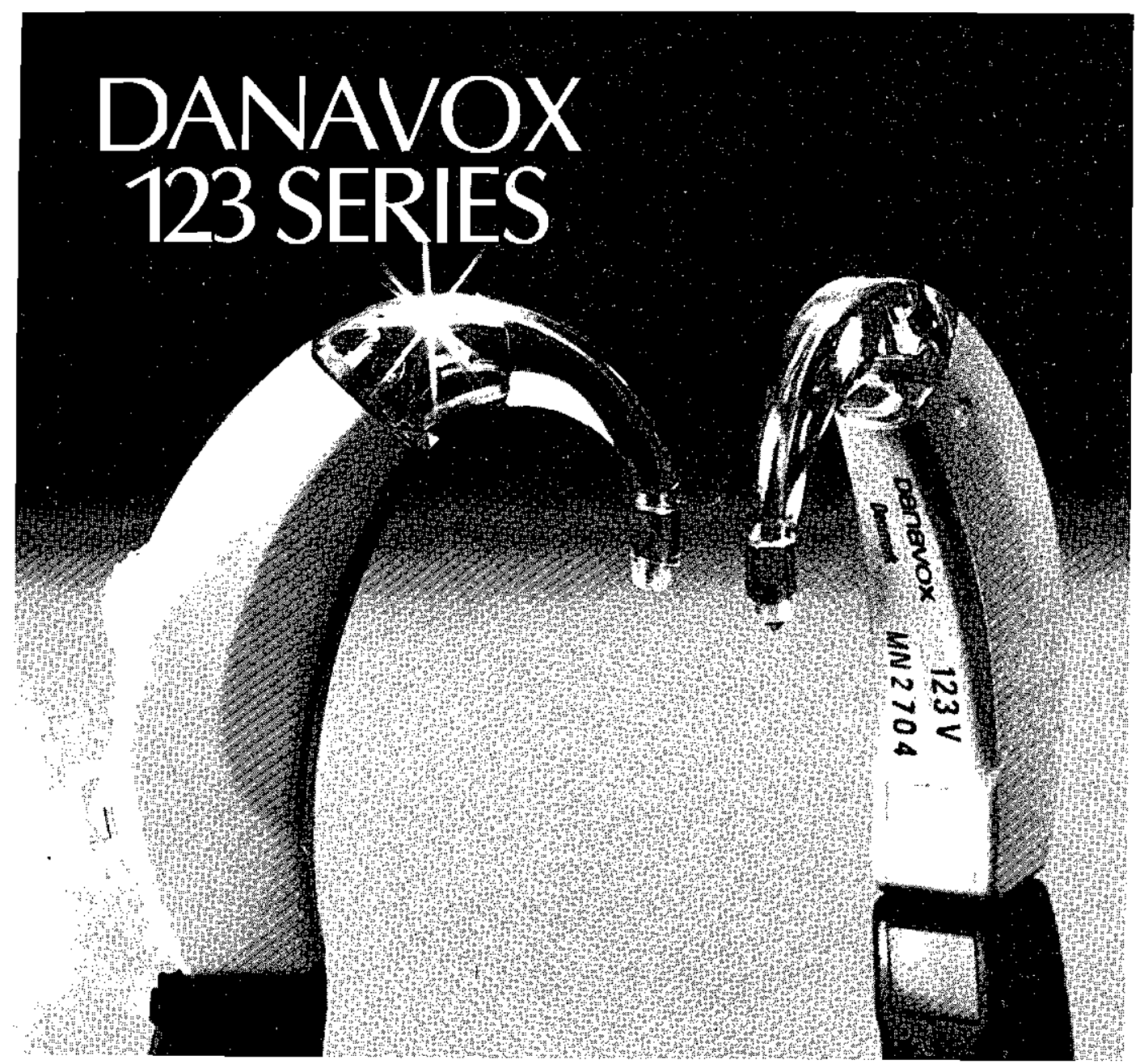

\section{Unique design, unrivalled technology and exceptional sound quality}

The 123 series is a completely new generation of small hearing aids combining an anatomically correct design with the latest in technology.

The 123 series offers the advantages of:

- modern, attractive design

- comfortable behind-the-ear fit

- convenient controls

- excellent sound quality and low distortion
- high degree of reliability

- gain unaffected by changes in battery voltage down to 1 volt

- very low battery consumption

\section{Danavox}

